\title{
Global and focal cerebral perfusion after aneurysmal subarachnoid hemorrhage in relation with delayed cerebral ischemia
}

\author{
M. Rijsdijk • I. C. van der Schaaf • B. K. Velthuis • \\ M. J. Wermer • G. J. E. Rinkel \\ Received: 6 December 2007 / Accepted: 14 May 2008 / Published online: 12 June 2008 \\ (C) The Author(s) 2008
}

\begin{abstract}
Introduction The pathogenesis of delayed cerebral ischemia (DCI) after subarachnoid hemorrhage (SAH) is unclear. We assessed whether DCI relates to focal or global cerebral perfusion on admission and on follow-up imaging.

Materials and methods Twenty-seven SAH patients underwent computed tomography (CT) perfusion (CTP) on admission and at clinical deterioration or 1 week after admission in clinically stable patients. We compared global and focal (least perfused territory) perfusion in patients with DCI $(n=12)$, clinically stable patients $(n=7)$, and patients with non-DCI-related deterioration $(n=8)$.

Results Global cerebral blood flow (CBF) increased on follow-up: $29 \%$ (95\% confidence interval (CI) $15 \%$ to $43 \%$ ) in patients with DCI, $12 \%(95 \% \mathrm{CI}-1 \%$ to $25 \%)$ in stable patients, and $20 \%(95 \% \mathrm{CI} 4 \%$ to $36 \%)$ in patients with nonDCI-related deterioration. Focal CBF decreased in patients with DCI, $(-23 \%$; $95 \% \mathrm{CI}-58 \%$ to $12 \%)$ but increased in patients with non-DCI-related deterioration $(23 \%$; $95 \% \mathrm{CI}$ $-26 \%$ to $55 \%$ ) and stable patients ( $7 \%$; $95 \% \mathrm{CI}-30 \%$ to $45 \%)$. On follow-up, global CBF was lower in patients with DCI (70.0 $\mathrm{ml} \mathrm{per} 100 \mathrm{~g} / \mathrm{min}$ ) than in clinically stable patients (81.6; difference 11.6 ; $95 \% \mathrm{CI} 0.8$ to $22.5 \mathrm{ml}$ per $100 \mathrm{~g} / \mathrm{min}$ ) but comparable to patients with non-DCI-related deterioration (67.6; difference $-2.4 ; 95 \% \mathrm{CI}-11.9$ to $7.2 \mathrm{ml}$ per $100 \mathrm{~g} / \mathrm{min}$ ). Focal CBF was lower in patients with DCI (30.7) than in clinically stable patients (53.6; difference 22.9 ; $95 \%$ CI 5.1 to
\end{abstract}

M. Rijsdijk • I. C. van der Schaaf $(\bowtie) \cdot B$. K. Velthuis Department of Radiology E01.132,

University Medical Center Utrecht,

P.O. Box 85500, 3508 GA Utrecht, The Netherlands

e-mail: i.vanderschaaf@umcutrecht.nl

\section{J. Wermer · G. J. E. Rinkel}

Department of Neurology from the Rudolf Magnus Institute for Neuroscience, University Medical Center, Utrecht, The Netherlands
$40.6 \mathrm{ml}$ per $100 \mathrm{~g} / \mathrm{min}$ ) and patients with non-DCI-related deterioration (46.6; difference 15.9 ; $95 \% \mathrm{CI}-2.6$ to $28.4 \mathrm{ml}$ per $100 \mathrm{~g} / \mathrm{min}$ )

Conclusion Our results suggest that DCI is more likely a focal than a global process.

Keywords Subarachnoid hemorrhage · Brain ischemia . $\mathrm{CT}$ perfusion $\cdot$ Cerebral autoregulation

\section{Introduction}

Delayed cerebral ischemia (DCI) is the most important complication leading to poor outcome in patients who survive the acute phase after subarachnoid hemorrhage (SAH) and in whom the aneurysm is occluded [1]. The pathogenesis of DCI is still unclear. Insight in the pathogenesis of DCI is important for advances in preventive treatment.

In the development of DCI, a cerebral perfusion deficit precedes the final infarction [2-4]. Whether the perfusion deficit reverses or evolves into infarction depends on the extent of the perfusion deficits and the autoregulation capacity $[5,6]$. The autoregulation mechanism is reported to be altered or defect in patients who develop DCI [4, 7-9].

Whether the pathogenesis of DCI is mainly a focal or a generalized process is unsettled [10]. Since treatment approaches for DCI are either systemic (e.g., triple $\mathrm{H}$ ) or focal (e.g., balloon dilatation of spastic vessels), the pathogenesis of DCI and whether it has a focal or global pathogenesis is of importance.

Besides DCI, SAH patients may also deteriorate from other causes such as hydrocephalus or metabolic disturbance. To assess whether perfusion deficits are specific for DCI or just a sign of deterioration in general, it is therefore important to compare cerebral perfusion in patients with DCI not only to that of clinically stable patients but also to patients with non-DCI-related deterioration. 
Since CT is used for follow-up of patients after SAH in most hospitals, CTP is a practical tool for clinical assessment of both focal and global cerebral perfusion. CTP allows quantitative measurements of cerebral perfusion on tissue level and provides information on cerebral blood volume (CBV), cerebral blood flow (CBF), and mean transit time (MTT).

The aim of this study was to assess whether DCI relates to focal or global cerebral perfusion on admission and on followup imaging and to compare global and focal perfusion in patients with DCI with that in clinically stable patients and in patients with clinical deterioration caused by hydrocephalus or metabolic disturbances.

\section{Materials and methods}

\section{Patients}

We prospectively studied a consecutive series of patients admitted to the University Medical Center Utrecht. If SAH was established on a noncontrast CT scan (NCCT), we immediately proceeded to CTP and CT angiography (CTA). Patients were included for the current study if the CTP scan was performed within $72 \mathrm{~h}$ after SAH and if they underwent a follow-up CTP scan within 14 days after SAH. Patients with SAH from causes other than a ruptured aneurysm, patients younger than 18 years of age, and patients with rebleeding during follow-up were excluded from the current study. For all patients, the clinical status on admission was assessed by means of the World Federation of Neurological Surgeons (WFNS) scale. [11] All patients were treated according to a standardized protocol that consisted of absolute bed rest until aneurysm treatment, administration of nimodipine, cessation of antihypertensive medication, and intravenous administration of fluid aiming for normovolemia. The admission CTP scan is standard clinical practice in our hospital. Informed consent for the study protocol was obtained from all patients. The study was approved by the ethics committee of the University Medical Center Utrecht.

\section{Imaging technique}

In our hospital, all patients with SAH routinely undergo NCCT, CTP, and CTA on admission. The CTA scan is used to diagnose and localize the ruptured aneurysm. The CTP scan is performed prior to CTA and replaces the timing scan for the CTA. All imaging studies were performed on a 16-slice spiral CT scanner (Philips M $\times 8000$ LDT, Best, the Netherlands). CTP source data were derived from sequential scans covering a slab of 2.4-cm thickness selected $3 \mathrm{~cm}$ above the sella turcica and angulated parallel to the meato-orbital line to contain the upper parts of the lateral ventricles and the basal ganglia. Forty milliliter of nonionic contrast agent (iopromide, Ultravist,
$300 \mathrm{mg}$ iodine per milliliter, Schering, Berlin, Germany) was injected into the cubital vein (18 gauge needle) at a rate of $5 \mathrm{ml} / \mathrm{s}$ followed by a $40 \mathrm{ml}$ saline flush at a rate of $5 \mathrm{ml} / \mathrm{s} \mathrm{using}$ a dual-power injector (Stellant Dual CT injector, Medrad Europe BV, Beek, the Netherlands). The following parameters were used: $90 \mathrm{kVp}, 150 \mathrm{mAs}, 8 \times 3$-mm collimation, $512 \times 512$ matrix, $200 \mathrm{~mm}$ field of view, one image per $2 \mathrm{~s}$ during $60 \mathrm{~s}$ (total 30 images), UB filter, and standard resolution.

\section{CTP measurements and data processing}

Follow-up NCCT and CTP scans were performed at time of the clinical deterioration. In patients who remained clinically stable, a scan was planned about 1 week after admission. CTP scans were reconstructed at $6-\mathrm{mm}$ contiguous axial images. Data were transferred to a Philips workstation for postprocessing. The quantitative cerebral perfusion measurements on CTP were based on temporal changes in signal intensity during the first pass of a bolus of an iodinated contrast agent. An arterial input function (AIF) and a venous output function (VOF; to correct for the partial volume effects of the AIF) were used in the calculations. The optimal AIF and VOF (voxels with the largest area under the curve (AUC) and an early arrival time of the contrast agent) were selected within the stack of 6-mm contiguous axial slices.

$\mathrm{CBV}$ was calculated as the ratio of the AUC of the first passage of the contrast agent through the tissue $\left(\mathrm{AUC}_{\text {tissue }}\right)$ to that of the AUC of the AIF $\left(\mathrm{AUC}_{\mathrm{AIF}}\right)$ with a correction factor $\mathrm{H}$ to account for the difference in the hematocrit in small versus large vessels: $\mathrm{CBV}=\mathrm{H} \times \mathrm{AUC}_{\text {tissue }} / \mathrm{AUC} \mathrm{AIF}_{\mathrm{AF}}$. The MTT, the average time taken by the blood to cross the capillary network, is calculated by means of deconvolution analysis [12]. The calculation of the CBF is based upon the "central volume principle," which states that the CBF is equal to the ratio of $\mathrm{CBV}$ and MTT: $\mathrm{CBF}=\mathrm{CBV} / \mathrm{MTT}$

CTP measurements were performed on both the admission and follow-up CTP scan. Eight regions of interest (ROIs) were drawn in the cortical gray matter or basal ganglia, bilateral in the peripheral flow territories of the anterior and middle cerebral artery (ACA and MCA, respectively) and bilateral in the deep flow territories of the ACA and MCA as presented in Fig. 1 and described in a previous article [13]. The ROIs were drawn by one of two observers blinded for the clinical condition of the patient (MR, IvdS). CTP measurements in the flow territory of the posterior cerebral artery were not included in this study.

\section{DCI and clinical deterioration}

Patients were divided into three groups according to their clinical course: (1) patients with clinical deterioration from DCI, (2) clinically stable patients, and (3) patients with 


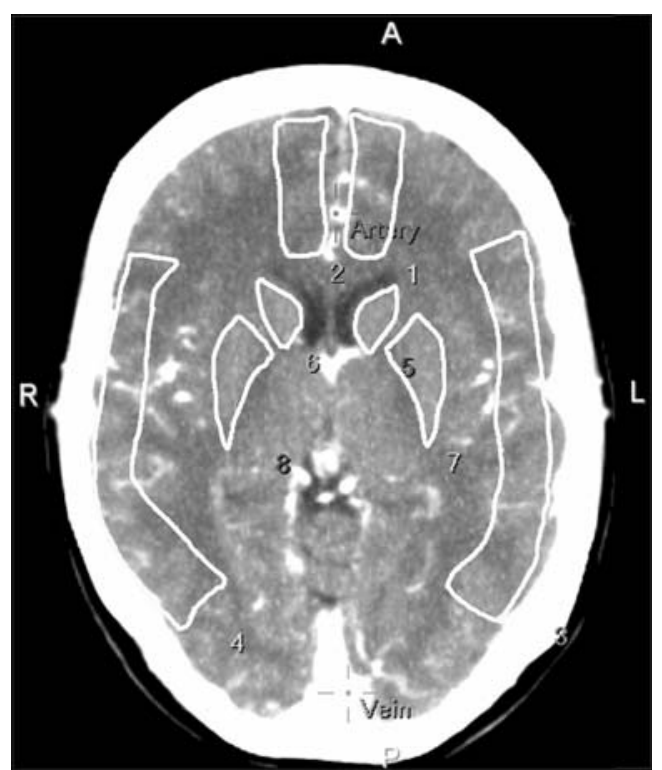

Fig. 1 Eight regions of interest in the cortical gray matter or basal ganglia for perfusion measurement

deterioration from hydrocephalus or metabolic disturbances (non-DCI-related deterioration).

The occurrence of DCI was assessed by a neurologist blinded for the CTP results. DCI was defined as a clinical deterioration (i.e., new focal deficit, decrease in consciousness, or both) lasting $2 \mathrm{~h}$ or longer with no evidence for rebleeding or hydrocephalus on CT and no other medical causes, such as infections or metabolic disturbances, and with or without hypodensity on CT. Non-DCI-related deterioration was defined as a decrease in Glasgow coma score of two points with the finding of hydrocephalus (bicaudatus index larger than 1) or other medical causes affecting the overall brain such as infection or metabolic disturbances. Infection was defined as: fever- leukocytosis-increased C-reactive protein along with clinical picture of infection for which antibiotic treatment was indicated.

Metabolic disturbances were defined as: hyponatremia or hypernatremia $(<125$ or $>155 \mathrm{mmol} / \mathrm{l})$, hypomagnesemia $(<0.6 \mathrm{mmol} / \mathrm{l})$, ionized hypercalcemia $(>1.3 \mathrm{mmol} / \mathrm{l})$. Patients with other causes for clinical deterioration such as cardiovascular complications or rebleeding were excluded.

Analysis

\section{Global cerebral perfusion}

First, the changes in global cerebral perfusion between admission and follow-up scan were compared between the three patient groups. For global cerebral perfusion on the admission scan, mean perfusion values of all eight ROIs per patient were calculated. On the follow-up scan, mean perfusion values of seven ROIs, excluding the least perfused
ROI (lowest quantitative values for $\mathrm{CBF}$ and $\mathrm{CBV}$ and highest quantitative values for MTT per patient), per patient were calculated. The least perfused ROI was excluded since extreme perfusion values (as in brain tissue with intracerebral hematoma or infarcted tissue) would influence global brain perfusion and thereby potentially bias the results. Mean perfusion values per patient group were charted.

We compared global cerebral perfusion on the follow-up scan between the different patient groups by calculating differences and $95 \%$ confidence intervals for patients with DCI versus clinically stable patients and versus patients with non-DCI-related deterioration.

\section{Focal cerebral perfusion}

Second, we studied the changes in focal cerebral perfusion between admission and follow-up scan for the three patient groups. Per scan, we selected the ROI with the least favorable perfusion. The least perfused flow territory on the initial and follow-up scan was not per definition located in the same flow territories. Mean focal perfusion values per patient group were calculated and charted.

We also compared differences in focal cerebral perfusion on follow-up for patients with DCI versus clinically stable patients and patients with non-DCI-related deterioration in a quantitative and semiquantitative manner. For the quantitative approach, again, ROIs with the least favorable perfusion values were selected. For the semiquantitative approach, we compared asymmetry in flow territories of contralateral hemispheres. We calculated ratios for $\mathrm{CBV}$ and $\mathrm{CBF}$ and differences for MTT for corresponding ROIs of both hemispheres. Per patient, the ROIs with the lowest $\mathrm{CBV}$ and CBF ratio and the largest MTT difference (reflecting the largest asymmetry in perfusion between both hemispheres) were selected.

For quantitative perfusion values, we calculated differences and $95 \%$ confidence intervals of the differences for patients with DCI versus clinically stable patients and versus patients with non-DCI-related deterioration. Semiquantitative values of the three patient groups (ratios and differences) were compared by means of the nonparametric Wilcoxon ranking score. A $p$ value less than 0.05 was considered statistically significant.

\section{Results}

Thirty-one patients met our inclusion criteria; however, in four patients, the follow-up scan was of too poor a quality due to movement of the patient (three patients) or due to inaccurate timing of the contrast administration (one patient) to allow analysis; thus, these four patients were excluded. In none of the included patients adverse side effects, such as 
contrast allergy, occurred. Of the 27 included patients, 12 developed DCI, seven remained clinically stable patients, and eight patients developed a clinical deterioration from hydrocephalus or metabolic derangement. The patient characteristics and time of the admission and follow-up scans of the 27 included patients are summarized in Table 1.

\section{Global cerebral perfusion}

Changes in global cerebral perfusion between admission and follow-up are presented in Fig. 2. Patients with DCI had the lowest global cerebral $\mathrm{CBF}$ and $\mathrm{CBV}$ values on admission which improved on the follow-up scan. CBF increased with $29 \%$, CBV increased with $10 \%$, and MTT decreased with $8 \%$. Clinically stable patients had the highest CBF and CBV values and lowest MTT values on admission. On follow-up, CBF increased with $12 \%$, CBV did not change, and MTT decreased with $9 \%$. Patients with non-DCI-related clinical deterioration had $\mathrm{CBF}$ values comparable to patients with DCI. CBF increased with $20 \%$, CBV increased with $2 \%$, and MTT decreased with $37 \%$. The follow-up global perfusion showed less favorable perfusion values in patients with DCI compared to clinically stable patients (CBF 14\% lower, CBV $8 \%$ lower, MTT $13 \%$ higher) and was equal to (CBV) or differed minimally (CBF $4 \%$ higher, MTT 7\% higher) from patients with non-DCI-related deterioration. (Table 2)

\section{Focal cerebral perfusion}

Changes in focal cerebral perfusion (least perfused flow territories) are shown in Fig. 2. Patients with DCI showed a decrease in focal $\mathrm{CBF}$ of $23 \%$ and $\mathrm{CBV}$ of $18 \%$ and an increase in focal cerebral MTT of 58\%. Clinically stable patients had an increase in focal CBF of $7 \%, \mathrm{CBV}$ of $12 \%$, and a decrease in focal cerebral MTT of $4 \%$. Patients with non-DCI-related clinical deterioration had an increasing CBF of $23 \%$, stable focal CBV, and decreasing MTT of $48 \%$. On follow-up, focal perfusion values were least favorable for patients with DCI; compared to clinically stable patients, CBF was $43 \%$ lower, CBV $27 \%$ lower, and MTT 90\% higher and compared to patients with non-DCI-related deterioration $\mathrm{CBF}$ was $34 \%$ lower, $\mathrm{CBV}$ was $17 \%$ lower, and MTT $80 \%$ higher. Differences were statistically significant for $\mathrm{CBV}$ and $\mathrm{CBF}$ values in patients with DCI compared to clinically stable patients. (Table 3 )

When comparing perfusion asymmetry (semiquantitative approach), patients with DCI showed more asymmetry in all perfusion values compared to both other patient groups. Differences in asymmetry were statistically significant except for asymmetry in CBF compared to clinically stable patients. (Table 3)

\section{Discussion}

Global cerebral perfusion on follow-up was less favorable in patients with DCI compared to clinically stable patients but was equal to(CBV) or differed marginally (CBF and MTT) from patients with non-DCI-related deterioration. Contrary to global perfusion, focal cerebral perfusion decreased between admission and follow-up scan in patients with DCI but increased in clinically stable patients and patients with nonDCI-related deterioration. In addition to decreased focal perfusion, patients with DCI had significantly more asymmetry in perfusion on follow-up compared to the other two patient groups. This indicates that, in the development of DCI, focal processes play a role. In patients with non-DCI-related deterioration, focal and global cerebral perfusion increased on follow-up, but global cerebral perfusion remained lower than in clinically stable patients. This indicates that not focal but mainly global processes are involved in the development of non-DCI-related clinical deterioration.

For a better understanding of the pathogenesis of DCI, we shall first discuss the acute phase after SAH in which several

Table 1 Patients characteristics.

\begin{tabular}{|c|c|c|c|c|}
\hline & $\begin{array}{l}\text { DCI } \\
(n=12)\end{array}$ & $\begin{array}{l}\text { Clinically } \\
\text { stable }(n=7)\end{array}$ & $\begin{array}{l}\text { Deteriorating without } \\
\text { DCI }(n=8)\end{array}$ & $\begin{array}{l}\text { Total } \\
(n=27)\end{array}$ \\
\hline Number of women $(\%)$ & $8(67 \%)$ & $7(100 \%)$ & $6(75 \%)$ & $21(78 \%)$ \\
\hline Mean age in years (range) & $59(38-84)$ & $49(36-63)$ & $62(46-73)$ & $57(36-84)$ \\
\hline \multicolumn{5}{|l|}{ WFNS grade (number of patients) } \\
\hline 1 & $1(8 \%)$ & $5(71 \%)$ & $3(38 \%)$ & $9(33 \%)$ \\
\hline 2 & $4(33 \%)$ & $1(14 \%)$ & $2(25 \%)$ & $7(26 \%)$ \\
\hline 3 & $2(17 \%)$ & 0 & 0 & $2(7 \%)$ \\
\hline 4 & $2(17 \%)$ & $1(14 \%)$ & 0 & $3(11 \%)$ \\
\hline 5 & $3(25 \%)$ & 0 & $3(38 \%)$ & $6(22 \%)$ \\
\hline $\begin{array}{l}\text { Mean days after SAH for admission } \\
\text { scan (range 0-3 days) }\end{array}$ & 0.7 & 1.1 & 0.5 & 0.7 \\
\hline $\begin{array}{l}\text { Mean days after SAH for follow-up } \\
\text { scan (range 2-14 days) }\end{array}$ & 7.3 & 9.1 & 6.8 & 7.6 \\
\hline
\end{tabular}


Fig. 2 Global (fat symbols) and focal (open symbols) perfusion on admission and follow-up in clinically stable patients (circle), patients with non-DCI-related deterioration (triangle), and patients with DCI (squares). a Changes in cerebral blood flow $(C B F$; milliliter per $100 \mathrm{~g} / \mathrm{min}), \mathbf{b}$ changes in cerebral blood volume $(C B V$; milliliter per $100 \mathrm{~g}$ ), and c changes in mean transit time (MTT; seconds)
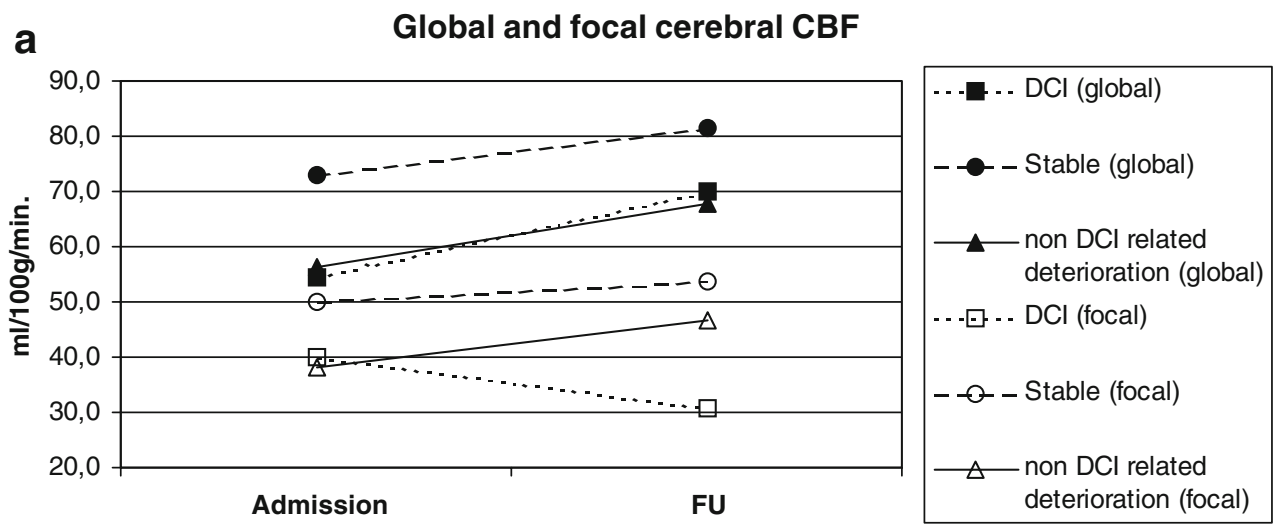

b
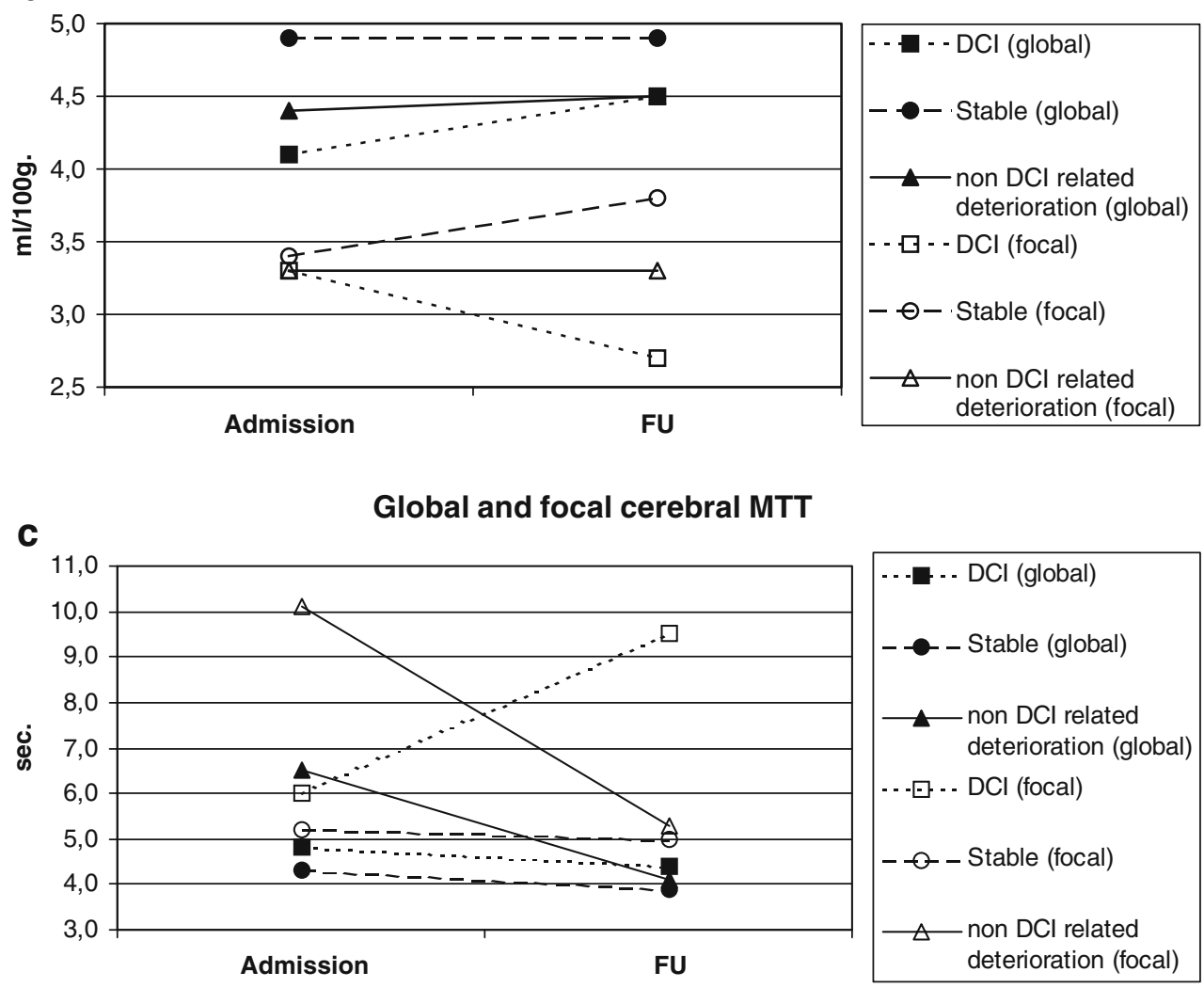

pathophysiologic and compensatory mechanisms are initiated. In the hyperacute stage after $\mathrm{SAH}$, intracranial pressure raises and cerebral perfusion pressure drops with consequently a decrease in CBF. [14, 15] In the compensation for this initial perfusion drop, cerebral autoregulation mechanisms play a role. If cerebral perfusion is compromised, cerebral autoregulation causes cerebral vasodilatation, reflected by an increased CBV. [16] If cerebral perfusion

Table 2 Follow-up global cerebral perfusion in patients with DCI, clinically stable patients, and patients with non-DCI-related deterioration.

\section{Clinically stable compared to DCI}

Perfusion parameter (mean)

CBF (milliliter per $100 \mathrm{~g} / \mathrm{min}$ )

CBV (milliliter per $100 \mathrm{~g}$ )

MTT (second)

DCI

DCI Clinically stable Difference $(95 \% \mathrm{CI})$

$\begin{array}{rrc}70.0 & 81.6 & 11.6(0.8 \text { to } 22.5) \\ 4.5 & 4.9 & 0.4(-0.01 \text { to } 0.8) \\ 4.4 & 3.9 & -0.5(-1.2 \text { to } 0.1)\end{array}$

Deteriorating without DCI compared to DCI

Deteriorating without DCI Difference (95\% CI)

67.6

4.5

4.1
$-2.4(-11.9$ to 7.2$)$

$-0.02(-0.5$ to 0.4$)$

$-0.3(-0.9$ to 0.3$)$ 
Table 3 Follow-up focal cerebral perfusion: least perfused flow territories and largest perfusion asymmetry.

\begin{tabular}{|c|c|c|c|c|c|}
\hline \multirow[t]{2}{*}{ Perfusion parameter } & \multicolumn{3}{|c|}{ Clinically stable compared to DCI } & \multicolumn{2}{|c|}{ Deteriorating without DCI compared to DC } \\
\hline & DCI & Clinically stable & $\begin{array}{l}\text { Difference }(95 \% \mathrm{CI}) \\
\text { Wilcoxon ranking score }^{\mathrm{a}}\end{array}$ & $\begin{array}{l}\text { Deterioration } \\
\text { without DCI }\end{array}$ & $\begin{array}{l}\text { Difference }(95 \% \mathrm{CI}) \\
\text { Wilcoxon ranking score }^{\mathrm{a}}\end{array}$ \\
\hline \multicolumn{6}{|l|}{ Quantitative $^{\mathrm{b}}$ (mean) } \\
\hline Lowest CBF (milliliter per $100 \mathrm{~g} / \mathrm{min}$ ) & 30.7 & 53.6 & $22.9(5.1$ to 40.6$)$ & 46.6 & $15.9(-2.6$ to 28.4$)$ \\
\hline Lowest CBV (milliliter per $100 \mathrm{~g}$ ) & 2.7 & 3.8 & $1.03(0.2$ to 1.9$)$ & 3.3 & $0.57(-0.3$ to 1.4$)$ \\
\hline Highest MTT (second) & 9.5 & 5.0 & $-4.52(-9.7$ to 0.7$)$ & 5.3 & $-4.22(-9.4$ to 1.0$)$ \\
\hline \multicolumn{6}{|l|}{ Semiquantitative $^{c}$ (median) } \\
\hline Lowest CBF (milliliter per $100 \mathrm{~g} / \mathrm{min}$ ) & 0.53 & 0.77 & 0.07 & 0.78 & 0.05 \\
\hline Lowest CBV (milliliter per $100 \mathrm{~g}$ ) & 0.65 & 0.85 & 0.03 & 0.78 & 0.05 \\
\hline Highest MTT (second) & 1.77 & 0.73 & 0.05 & 0.70 & 0.009 \\
\hline
\end{tabular}

${ }^{\text {a }}$ Difference $(95 \% \mathrm{CI})$ for quantitative; Wilcoxon ranking score for semiquantitative

${ }^{\mathrm{b}}$ Quantitative: mean values of the least perfused flow territories

${ }^{\mathrm{c}}$ Semiquantitative: ratio's of CBV and CBF and difference of MTT corresponding to the flow territory with the largest asymmetry

decreases further and the ability of vessels to dilate is exhausted, the CBF starts to decrease. The brain can compensate for this by increasing the extraction of oxygen from the blood. This is enabled by a prolonged MTT since the slow flow of blood results in greater extraction of oxygen. [16]

In the present study, patients were scanned on admission in the subacute phase after SAH. Clinically stable patients had initially highest global brain CBF values compared to patients with clinical deterioration and showed an increasing CBV, which represents adequate autoregulation. Patients with DCI had initially lowest global brain CBF values in combination with lowest $\mathrm{CBV}$ values and an only slightly raised MTT indicating that cerebral autoregulation was inadequate. These reported changes in cerebral perfusion are beyond chance since statistically significant differences in focal cerebral perfusion with corresponding trends in global cerebral perfusion are observed, despite the relatively small number of patients included in each group. Also, our results correspond with the results in two articles measuring cerebral perfusion in the first 3 weeks after SAH. [17, 18] The concept of impaired autoregulation mechanisms on admission in patients who later develop DCI has also been described in other articles. [4, 7, 9, 13, 15, 19]

This study also showed that CTP is a practical and useful tool to compare perfusion on admission and during follow-up in patients with SAH since in $87 \%$ of patients a good quality admission and follow-up scan was obtained and no side effects of the CT scanning with contrast occurred. Often, transcranial Doppler (TCD) monitoring is used for follow-up monitoring in patients with $\mathrm{SAH}$ for the presence of vasospasm. TCD, however, cannot be used to quantify $\mathrm{CBF}$ at the tissue level and sensitivity is high for the middle cerebral artery but low for the other vessels. [20] Other techniques to measure brain perfusion include positron emission tomography, single-photon emission tomography, xenon-enhanced CT, and perfusion magnetic resonance imaging. [21]
However, these techniques have limited clinical access, in particular for patients who are restless or ventilated. In patients with neurological deterioration, it is standard clinical practice to perform an NCCT scan for detection or exclusion of hydrocephalus, rebleed, or infarction. CTP can be performed directly after this NCCT scan and can serve for the timing scan for CTA. The postprocessing and measurements of CTP could be performed within $5 \mathrm{~min}$. Therefore, CTP is practical in the clinical setting.

Controversies exist regarding the quantitative perfusion values of CTP although CTP has been validated many times in animal and human models. [22] Our quantitative perfusion values were within the range described by other groups. [17, 23] Also, our semiquantitative analyses were in the same line as the quantitative findings, which further supports the validity of our quantitative measures.

A disadvantage of measuring cerebral perfusion by means of CTP is the limited brain volume included in the perfusion slab. In this study, the perfusion slab measured $2.4 \mathrm{~cm}$ and thus represents only a certain proportion of the total brain parenchyma. Since this slice was located on the level of the basal ganglia, we think that the brain structures most prone to DCI were included in the slab. However, we might have missed locations with more severe perfusion deficits in other parts of the brain. Also, we measured perfusion in predefined ROIs. Again, more severe perfusion deficits might have been located outside or partly inside the ROI. This limitation accounts for all patients. If this problem would have biased our results, it would be towards less relation and thus stronger relations are expected when measuring the most severe perfusion deficits in whole-brain volumes. By using CT scanners with increasing detector rows, the problem of limited scan volume will be resolved.

In the present study, we investigated differences in global and focal cerebral perfusion in patient groups to obtain more knowledge on the pathogenesis of DCI. Subsequently, this 
knowledge can be used to study individual patient data and determine what diagnostic and prognostic information can be derived from their CTP scan results. Future research could elaborate the value of individual measurements.

Clinically stable patients were younger than both groups of patients with clinical deterioration. Cerebral perfusion decreases with age. The average annual overall decrease in normal gray matter is around $0.37 \%$ to $0.45 \%$. [24] Even if $0.45 \%$ decrease per year is taken into account, the difference in age cannot explain the discrepancy in perfusion between the three patient groups. Patients later developing DCI or non-DCI-related clinical deterioration had more severe WFNS grades on admission than clinically stable patients. Clinical condition is considered as an expression of cerebral perfusion. Research provided evidence for the predictive value of clinical condition on admission in the development of DCI. [25] In the present study, we studied global and focal cerebral perfusion after SAH and its relation with DCI and not the predictive value of cerebral perfusion on admission in the development of DCI. Therefore, clinical condition is not a biasing factor for the relation between global and focal cerebral perfusion and the development of DCI.

For current medical treatment for reversing DCI, a combination of hypertension, hypervolemia, and hemodilution (triple $\mathrm{H}$ ), or other treatment as for example balloon angioplasty, efficacy has not been proven by means of randomized clinical trials. [26, 27] Therefore, monitoring effects of these treatment strategies is of importance. This study shows that CTP offers a feasible method in patients with SAH for monitoring of cerebral perfusion and allows comparison of perfusion values between two scans. Therefore, CTP might be useful to study the effects of different treatment strategies for DCI on cerebral perfusion and the occurrence of DCI.

\section{Conclusion}

The present study demonstrates that CTP is a suitable tool to compare cerebral perfusion on admission and follow-up. All patients had an improved global perfusion during follow-up. Focal perfusion however decreased on follow-up in patients with DCI but not in patients with non-DCI-related deterioration or clinically stable patients, and patients with DCI had least favorable focal perfusion values on follow-up. This suggests that DCI is more likely a focal than a global process.

Acknowledgments This study was supported by an NWO grant to I.C. van der Schaaf.

Conflict of interest statement We declare that we have no conflict of interest.
Open Access This article is distributed under the terms of the Creative Commons Attribution Noncommercial License which permits any noncommercial use, distribution, and reproduction in any medium, provided the original author(s) and source are credited.

\section{References}

1. van Gijn J, Rinkel GJ (2001) Subarachnoid haemorrhage: diagnosis, causes and management. Brain 124:249-278

2. Powers WJ, Grubb RL Jr., Baker RP, Mintun MA, Raichle ME (1985) Regional cerebral blood flow and metabolism in reversible ischemia due to vasospasm. Determination by positron emission tomography. J Neurosurg 62:539-546

3. Yonas H, Sekhar L, Johnson DW, Gur D (1989) Determination of irreversible ischemia by xenon-enhanced computed tomographic monitoring of cerebral blood flow in patients with symptomatic vasospasm. Neurosurgery 24:368-372

4. Yundt KD, Grubb RL Jr, Diringer MN, Powers WJ (1998) Autoregulatory vasodilation of parenchymal vessels is impaired during cerebral vasospasm. J Cereb Blood Flow Metab 18:419-424

5. Fainardi E, Tagliaferri MF, Compagnone C, Tanfani A, Cocciolo F, Battaglia R, Frattarelli M, Pascarella R, Targa L, Chieregato A (2006) Regional cerebral blood flow levels as measured by xenon$\mathrm{CT}$ in vascular territorial low-density areas after subarachnoid hemorrhage are not always ischemic. Neuroradiology 48:685-690

6. Kaufmann AM, Firlik AD, Fukui MB, Wechsler LR, Jungries CA, Yonas H (1999) Ischemic core and penumbra in human stroke. Stroke 30:93-99

7. Lam JM, Smielewski P, Czosnyka M, Pickard JD, Kirkpatrick PJ (2000) Predicting delayed ischemic deficits after aneurysmal subarachnoid hemorrhage using a transient hyperemic response test of cerebral autoregulation. Neurosurgery 47:819-825

8. Sakowitz OW, Unterberg AW (2006) Detecting and treating microvascular ischemia after subarachnoid hemorrhage. Curr Opin Crit Care 12:103-111

9. Voldby B, Enevoldsen EM, Jensen FT (1985) Cerebrovascular reactivity in patients with ruptured intracranial aneurysms. J Neurosurg 62:59-67

10. Stein SC, Levine JM, Nagpal S, LeRoux PD (2006) Vasospasm as the sole cause of cerebral ischemia: how strong is the evidence? Neurosurg Focus 21:E2

11. Anonymous. Report of World Federation of Neurological Surgeons Committee on a universal subarachnoid hemorrhage grading scale. J Neurosurg 68:985-986

12. Axel L (1980) Cerebral blood flow determination by rapid-sequence computed tomography: theoretical analysis. Radiology 137:679-686

13. van der Schaaf I, Wermer MJ, van der Graaf Y, Hoff RG, Rinkel GJ, Velthuis BK (2006) CT after subarachnoid hemorrhage: relation of cerebral perfusion to delayed cerebral ischemia. Neurology 66:15331538

14. Grote E, Hassler W (1988) The critical first minutes after subarachnoid hemorrhage. Neurosurgery 22:654-661

15. Lang EW, Diehl RR, Mehdorn HM (2001) Cerebral autoregulation testing after aneurysmal subarachnoid hemorrhage: the phase relationship between arterial blood pressure and cerebral blood flow velocity. Crit Care Med 29:158-163

16. Grubb RL Jr, Raichle ME, Eichling JO, Gado MH (1977) Effects of subarachnoid hemorrhage on cerebral blood volume, blood flow, and oxygen utilization in humans. J Neurosurg 46:446-453

17. Nabavi DG, LeBlanc LM, Baxter B, Lee DH, Fox AJ, Lownie SP, Ferguson GG, Craen RA, Gelb AW, Lee TY (2001) Monitoring cerebral perfusion after subarachnoid hemorrhage using CT. Neuroradiology 43:7-16 
18. Talacchi A (1993) Sequential measurements of cerebral blood flow in the acute phase of subarachnoid hemorrhage. J Neurosurg Sci 37:9-18

19. Jakubowski J, Bell BA, Symon L, Zawirski MB, Francis DM (1982) A primate model of subarachnoid hemorrhage: change in regional cerebral blood flow, autoregulation carbon dioxide reactivity, and central conduction time. Stroke 13:601-611

20. Proust F, Debono B, Gerardin E, Hannequin D, Derrey S, Langlois O, Weber J, Freger P (2002) Angiographic cerebral vasospasm and delayed ischemic deficit on anterior part of the circle of Willis. Usefulness of transcranial Doppler. Neurochirurgie 48:489-499

21. Latchaw RE, Yonas H, Hunter GJ, Yuh WT, Ueda T, Sorensen AG, Sunshine JL, Biller J, Wechsler L, Higashida R, Hademenos G (2003) Guidelines and recommendations for perfusion imaging in cerebral ischemia: a scientific statement for healthcare professionals by the writing group on perfusion imaging, from the Council on Cardiovascular Radiology of the American Heart Association. Stroke 34:1084-1104

22. Wintermark M, Flanders AE, Velthuis B, Meuli R, van LM, Goldsher D, Pineda C, Serena J, van der Schaaf I, Waaijer A, Anderson J, Nesbit G, Gabriely I, Medina V, Quiles A, Pohlman
S, Quist M, Schnyder P, Bogousslavsky J, Dillon WP, Pedraza S (2006) Perfusion-CT assessment of infarct core and penumbra: receiver operating characteristic curve analysis in 130 patients suspected of acute hemispheric stroke. Stroke 37:979-985

23. Harrigan MR, Magnano CR, Guterman LR, Hopkins LN (2005) Computed tomographic perfusion in the management of aneurysmal subarachnoid hemorrhage: new application of an existent technique. Neurosurgery 56:304-317

24. Parkes LM, Rashid W, Chard DT, Tofts PS (2004) Normal cerebral perfusion measurements using arterial spin labeling: reproducibility, stability, and age and gender effects. Magn Reson Med 51:736-743

25. van der Schaaf I, Wermer MJ, van der Graaf Y, Velthuis BK, van de Kraats CI, Rinkel GJ (2006) Prognostic value of cerebral perfusion-computed tomography in the acute stage after subarachnoid hemorrhage for the development of delayed cerebral ischemia. Stroke 37:409-413

26. Myburgh JA (2005) "Triple h" therapy for aneurysmal subarachnoid haemorrhage: real therapy or chasing numbers? Crit Care Resusc 7:206-212

27. Suarez JI, Tarr RW, Selman WR (2006) Aneurysmal subarachnoid hemorrhage. N Engl J Med 354:387-396 